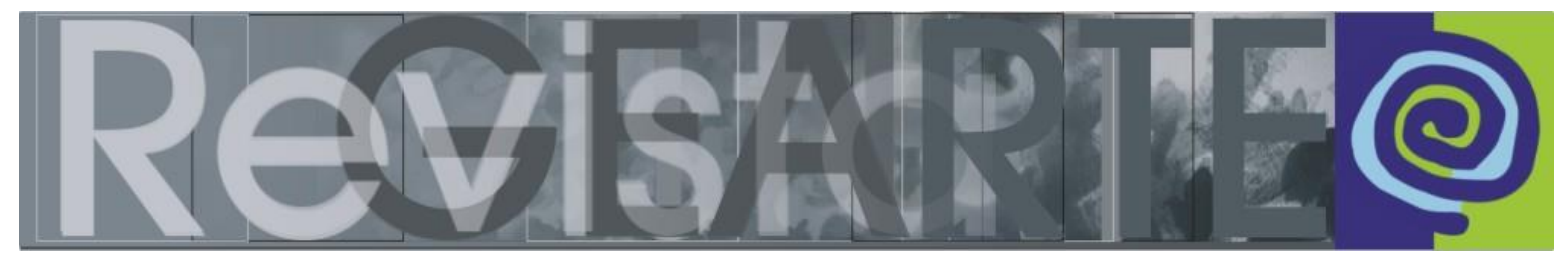

Volume 1, Número 1, Abril/2014, ISSN 2357-9854

\title{
Criando fluxos de investigações efervescentes entre Espanha e Brasil
}

\author{
María Acaso (UCM - Espanha) \\ Analice Dutra Pillar (UFRGS - Brasil)
}

\section{RESUMO}

Neste texto, María Acaso, coordenadora do coletivo Pedagogías Invisibles (Espanha) e Analice Pillar, coordenadora do Grupo de Pesquisa em Educação e Arte (GEARTE - Brasil), compartilham as principais linhas de pesquisa desses coletivos com a intenção de criar redes de intercâmbio entre ambas as comunidades para mesclar, contaminar e, portanto, transformar os dois grupos. O texto busca apontar afinidades entre os trabalhos que estão sendo realizados nos referidos grupos transdisciplinares e transoceânicos.

\section{PALAVRAS-CHAVE}

Pedagogías Invisibles; GEARTE; grupo de pesquisa; redes de pesquisa.

\section{ABSTRACT}

In this text, María Acaso, coordinator from the collective Invisible Pedagogies (Pedagogías Invisibles Spain), and Analice Pillar, coordinator from the Group of Research in Education and Art (GEARTE Brazil), share the main lines of research of these collectives intending to develop an exchange network between both communities in order to meld, contaminate and, then, transform these groups. This text aims to point out the affinity between the researches developed by these two transdiciplinary and transoceanic groups.

\section{KEYWORDS}

Invisible Pedagogies; GEARTE; group of research, network of research

\section{Da palavra ao coletivo Pedagogias Invisíveis ${ }^{1}$}

Existem algumas forças invisíveis, que parecem ter maior importância que as visíveis e que utilizam a linguagem visual como principal ferramenta para transmitir conteúdos em aula e em outros contextos onde a aprendizagem ocorre. Quando decidi buscar mais informação sobre esse assunto, percebi que os autores que trabalham sobre o currículo oculto (Giroux, McLaren, Kincheloe) se centram nas mensagens que são transmitidas através da linguagem oral e da linguagem escrita, mas não há nada sobre a linguagem visual.

A inexistência de literatura que conecte o currículo oculto com a linguagem visual me levou, em 2005, a escrever o artigo El currículum oculto visual: aprender a obedecer a través de la imagen (ACASO; NUERE, 2005), que reúne tudo o que vinha

\footnotetext{
1 Uma abordagem mais detalhada da criação do coletivo Pedagogías Invisibles está na obra de mesmo nome Pedagogías invisibles: el espacio del aula como discurso (ACASO, 2012). Esta parte do texto traz, de forma sintética, algumas ideias apresentadas no livro.
} 
trabalhando até aquele momento (semiótica, linguagem visual e currículo oculto) e avança a ideia de que é necessário criar um protocolo não para que semiólogos, artistas ou publicitários sejam capazes de decompor os produtos visuais que nos rodeiam, mas para possibilitar que os educadores e o restante dos profissionais que se dedicam à educação sejam capazes de decompor os produtos visuais e as imagens que existem em seus contextos de trabalho. Este texto representa um salto muito importante, um salto no qual me dou conta da necessidade de unir a semiótica com a pedagogia, as artes e a cultura visual. Ressalto algo que nasce nesse momento: nosso interesse não se centra em desenvolver um manual de semiótica visual para professores, um manual que conecte a semiótica geral para docentes e que utilizem fora da aula. Não. O que queremos é construir um manual de semiótica pedagógica, ou seja, um manual para que qualquer profissional que se dedique à educação entenda seu trabalho como uma sucessão de atos que configuram um discurso que deve ser analisado do ponto de vista de seu significado e que utilize em aula. Essa diferença é muito importante.

Em setembro de 2009, quando o grupo de doutorandos e eu realmente já não tínhamos que nos reunir para nada, decidimos continuar. Estava começando um grupo de autodoutorado no qual, ao longo dos meses, iríamos discutindo as teses e nos ajudando mutuamente, fazendo de cada trabalho individual uma espécie de pesquisa coletiva. Já não havia créditos envolvidos, nem notas, nem nenhum tipo de dependência forçada pelo medo e pela resignação acadêmica; reuníamo-nos para continuar com a nossa paixão pela aprendizagem e esse é o momento que podemos marcar como ponto fixo no contínuo espaço-tempo em que surgiu Pedagogias Invisíveis.

Os nomes que são dados às coisas me parecem realmente importantes e não desejávamos utilizar um meramente descritivo; queríamos buscar um termo que em poucas palavras resumisse o trabalho que estávamos realizando a respeito dos mundos visuais que nos rodeiam. Também é nesse momento que decidimos trabalhar sobre três grandes âmbitos: a educação secundária obrigatória, a educação superior das artes visuais e a educação em museus de artes visuais.

Já no ano de 2010, conscientes de nossa condição de coletivo a meio caminho entre a educação, a criação artística e a pesquisa, nos envolvemos totalmente na 
produção cultural com a organização do nosso primeiro grande evento, junto com Ana Moreno, do Museu Thyssen, e Carla Padró, da Universidad de Barcelona (UB): Quem essa cadeira pensa que você é? (março de 2010), em que se realizou um seminário de três dias durante os quais Elizabeth Ellsworth e a artista Jamie Kruse estiveram na Faculdade de Belas Artes da Universidad Complutense de Madrid (UCM) com estudantes de todo o espectro acadêmico, no Museu Thyssen com educadoras de museus e pesquisadoras e na Faculdade de Belas Artes da UB com os estudantes de doutorado e mestrado de Carla. Nas três instituições, o trajeto de suas palavras foi tão reconstituinte, tão empoderador e tão criativo que conseguiu nos transformar e também conseguiu que nós transformássemos os outros. Fruto desse encontro, no ano de 2011 é publicado o texto em que Carla, Elizabeth e eu realizamos uma conversa sobre outras formas de fazer pedagogia, o qual recebe o nome de $E I$ aprendizaje de lo inesperado (ACASO; ELLSWORTH, 2011).

Nesse mesmo mês, nos apresentamos pela primeira vez como coletivo, no Terceiro Congresso Internacional de Educação Artística e Visual em Málaga (2010), e realizamos nossa primeira comunicação conjunta, à qual se seguiria outra em Valência no mesmo ano, onde realizamos uma comparação entre as pedagogias invisíveis de quatro centros expositivos de artes visuais: o PS1, em Nova York; o Círculo de Belas Artes e a Fundação Juan March, em Madri; e Manifesta 8, em Múrcia, onde resumimos nossa atividade no terreno específico dos museus de artes visuais.

Através de outra coincidência, em dezembro de 2010 descobrimos o livro El Proyecto Facebook y la posuniversidad (PISCITELLI; ADAIME; BINDER, 2010), cujo prólogo, escrito por Alejandro Piscitelli, desatou uma segunda revolução centrada, nesse caso, na necessidade de mudança de formatos e no edupunk. A partir desse livro, decidimos criar outro evento-seminário: Edupunk e pós-universidade: os doutorados têm sentido em tempos de Facebook? (março de 2011). Para o evento, contamos com a presença do próprio Piscitelli. Esse foi outro ponto de inflexão para nós, porque nos demos conta de algo que suspeitávamos há tempos, pode ser que os nossos conteúdos sejam muito atuais e progressivos, mas se o formato que utilizamos para comunicar tais conteúdos não o é (e estamos utilizando uma aula magistral), estamos entrando em uma profunda contradição. 
No mês seguinte, em 4 de abril de 2011, vai ao ar o programa Miradas Invisibles, na Rádio Círculo, o primeiro programa sobre arte e educação do qual temos notícia. Nossa motivação ao iniciá-lo foi criar uma nova via de difusão das pesquisas, eventos e publicações relacionados com os temas de pesquisa do coletivo. Existe uma carência de informação nos meios de comunicação sobre essas temáticas, que consideramos fundamentais, e queríamos contribuir para a mudança desde um formato como o radiofônico. Com o tempo descobrimos que também se trata de um sistema para realizar conexões entre profissionais, já que permite compartilhar as experiências de outros escutando o programa e, além disso, que sejam criadas relações a partir do rádio, nesse caso usado como uma ponte para que a pesquisa de doutorado saia dos muros da Academia.

Uma vez consolidado nosso trabalho como produtores de eventos, também em 2011 damos o salto em direção à produção de projetos educativos, dessa vez de mãos dadas com Matadero Madrid: En Construcción, disculpen las molestias. O projeto que desenvolvemos para Matadero tem como objetivo propor uma ação cultural performativa para o público de zero a 99 anos que vai a esse centro. Esse trabalho nos proporciona a oportunidade de desenvolver na prática educativa o que estávamos debatendo, mediante a realização de nossas pesquisas e eventos: utilizar a arte contemporânea como formato (performance), o corpo dos participantes como suporte, sair do recinto habitual onde se faz o didático (os habituais espaços de oficinas), prolongar a ação educativa em todo o espaço disponível (o hall, o pátio, o próprio espaço da exposição...), romper a homogeneidade do público ao fazer uma oficina de zero a 99 anos, prescindir do mobiliário tradicional, repartir o poder (éramos três pessoas fazendo a oficina), e, tudo isso, sem fazer trabalhos manuais.

Em setembro desse mesmo ano, Idensitat entra em contato com Pedagogias Invisíveis para colaborar durante a exposição do projeto Post-it City no Centro-Centro de Madrid. Participamos com a realização de cinco oficinas em diferentes contextos nos quais trabalhamos: institutos de Ensino Médio, hospitais e o bairro de Lavapiés. Nesses cinco projetos abordamos os possíveis usos e apropriações temporais do espaço público a partir dos discursos não explícitos.

Já em outubro, a Fundação Telefônica nos convida para participar em Educared 2011, onde realizamos uma oficina adaptada às circunstâncias. 
Encontramo-nos com um espaço gigantesco, totalmente impessoal e dividido em cubículos, transitado por participantes que escreviam a cada passo, que se sentavam muito docilmente para escutar os palestrantes, os quais se situavam em pedestais com poltronas de couro, e que tinham que cumprir com um certo número de horas para conseguir o desejado certificado. Se nosso objetivo era desvelar as pedagogias invisíveis em qualquer contexto educativo, também o faríamos nesse, e o fizemos trabalhando no formato do recinto da feira como lugar de aprendizagem.

No ano de 2012, nosso trabalho dá um salto qualitativo muito importante na parte de criação de projetos, começando com a abertura do Espacio Visible en El Ranchito (Matadero Madrid), no mesmo dia em que assinamos e nos configuramos como associação. No Espacio Visible é possível uma produção reflexiva e criativa por parte do público, para articular um novo contexto no qual ele se integre na qualidade de colaborador, implicando-o em El Ranchito no processo criativo e gerando um espaço de encontro e visibilidade. Um dos principais recursos desenvolvidos para isso foram as oficinas intergeracionais: (0-99), nas quais foram trabalhados os conceitos de "laboratório", "conexões (ponte-conectores)" e "cidade". Além disso, também tivemos a possibilidade de desenvolver processos colaborativos com os coletivos Excedentes-Excess e HUSOS, participando no projeto, coordenação e dinamização das respectivas mesas de debate.

Embora a maioria dos que compomos Pedagogias Invisíveis vimos de faculdades de Belas Artes, também cursamos História da Arte ou Pedagogia. Em qualquer caso, nossa área de estudo é o ensino da $a_{r t e}{ }^{2}$ e, como já vimos antes, em três contextos principais: a Educação Secundária, os museus e o que começamos a denominar como contextos comunitários. Consideramos muito importante a dissolução das disciplinas (de fato, estamos abertamente contra elas) e, devido a essa vontade de dissolução, também queremos migrar do ensino da arte para outros campos.

Encontramos outras zonas de estudo extremamente atrativas como a cultura visual, a cartografia, a antropologia, a história da arte, a psicanálise e os estudos

\footnotetext{
${ }^{2}$ No texto original, a autora usa o termo educação artística, que é a denominação oficial para o ensino da arte na Espanha. Como no Brasil o termo utilizado é ensino da arte, o adotamos para fazer referência à terminologia espanhola.
} 
feministas e consideramos que essa é a chave para criar uma releitura das pedagogias modernistas que nos levem a desenvolver o corpo do que começamos a chamar pedagogias contemporâneas.

As pedagogias invisíveis resultam de um híbrido entre semiótica e pedagogia, de forma que podemos dizer que, embora seja um termo que nasce no âmbito do ensino da arte, se desdobra para qualquer processo relacionado com a educação. No fundo, tratamos de processos semióticos que deveriam ser instaurados na cotidianidade e em qualquer campo de estudo, porque, quando analisamos um filme ou a indumentária de alguém, estamos realizando uma análise semiótica. O que queremos discutir e o que nos preocupa como coletivo é que esses processos de análise semiótica não se realizem no pedagógico, processos que estão mais ou menos em consenso nas artes, na publicidade e nos estudos fílmicos, mas que nos contextos educativos (sejam formais ou informais, sejam na escola ou em nossa própria casa) o processo de refletir e analisar sobre os usos da linguagem e, de forma específica, da linguagem visual, não esteja entendido como hábito.

O termo pedagogias invisíveis nasce de uma mescla da obra de Elizabeth Ellsworth (ELLSWORTH, 2005) com a semiótica visual, ao resgatar, a partir dos tratados de semiótica, os conceitos de direcionalidade, denotativo e conotativo ou discurso implícito e discurso explícito e levá-los à sala de aula, à escola e a outros contextos educativos emergentes. Resgatamos a ideia do pedagogo norte-americano Philip Jackson e a mesclamos com Eco e com Peirce, enriquecendo a pedagogia com a semiótica geral, com a semiótica visual, com a semiótica do espaço, começamos a alinhavar uma semiótica do ato pedagógico. Fundamentalmente nos apoiamos em Peirce e na divisão entre o denotativo e o conotativo para definir o que são as pedagogias invisíveis como a parte conotativa do discurso educativo, não a parte conotativa do discurso oculto, mas a parte conotativa do discurso explícito, a elaboração cultural subjetiva daquilo que temos debaixo do nosso nariz, como, por exemplo, fazer uma revisão feminista de uma escultura sem cabeça ou de uma apresentação em PowerPoint na qual em todos os exemplos de educação antiquada aparece uma professora rural e, por outro lado, em todos os exemplos de educação inovadora aparece um professor de Harvard... 
Nosso desejo, com agentes sociais, é transformar a realidade através de ações semióticas, desenvolver uma hermenêutica da suspeita que nos leve a repensar nosso trabalho como docentes: não ficamos contentes se somente detectamos e analisamos, pois detectar e analisar devem conduzir a mudar o que não funciona, a manter o que acreditamos que funciona e a mudar o que funciona para nós, mas não para os outros.

Nos sentimos nas margens. E é nesse trajeto pelas margens onde nasce nossa paixão por levar a pedagogia a lugares não habituais para ela. Para olhá-la com um olhar cálido e transformá-la, deixar de abordá-la como uma disciplina para começar a olhá-la como um desafio. Esse é o ponto que nos une (bom, e mais algumas coisas, como o mate e bolinhos).

\section{O Grupo de Pesquisa em Educação e Arte (GEARTE)}

A ideia de criação de um grupo de pesquisa sobre arte e educação começou nos seminários de dissertação e tese do meu grupo de alunos de mestrado e doutorado do Programa de Pós-graduação em Educação da Faculdade de Educação da Universidade Federal do Rio Grande do Sul (UFRGS). Em 20 de junho de 1997, em um encontro em que estavam professores de artes visuais, teatro, música e educação infantil decidimos criar o Grupo de Pesquisa em Educação e Arte (GEARTE) ${ }^{3}$, um dos primeiros grupos de arte/educação no Brasil, inscrito no Diretório de Grupos de Pesquisas do Conselho Nacional de Desenvolvimento Científico e Tecnológico (CNPq/Brasil).

Nosso desejo era aprofundar os estudos sobre a construção do conhecimento nas artes e as formas de tratar a arte na educação formal e não formal. Em 1996, a nova Lei de Diretrizes e Bases da Educação Brasileira foi promulgada criando a disciplina Arte no currículo escolar e os professores da área estavam muito mobilizados politicamente em defesa da qualificação do ensino da arte. Nesse momento, era necessário destacar a arte como um campo de conhecimento (Goodman, Gardner e Eisner) para mostrar sua relevância na escola. Então, importava qualificar o ensino da arte através da formação de docentes e de apoio

\footnotetext{
${ }^{3}$ Gostaria de referir a importante acolhida e incentivo que tivemos naquele momento do coordenador do Programa de Pós-Graduação em Educação da UFRGS, professor Dr. Nilton Fischer.
} 
teórico e metodológico para sua prática na escola. No Brasil havia poucos estudos nessa perspectiva, sendo importante destacar os trabalhos de Ana Mae Barbosa, especialmente a Abordagem Triangularque proporcionou, em princípios de 1990, uma mudança política e conceitual ao repensar o ensino da arte como produção, leitura e contextualização.

No final de 1990 e início do novo milênio, nossas pesquisas se centraram nos processos de construção de conhecimento em arte focalizando a criação nas linguagens artísticas, seja nas artes visuais, no teatro ou na música; a compreensão estética; a formação estética dos professores; e as interações em espaços de educação formal e informal. Para difundir nossos estudos, organizamos o livro $A$ educação do olhar no ensino das artes (PILLAR, 2011), que tem sido uma referência para muitos trabalhos na área da leitura de imagens. Com interesse na grande influência da televisão na constituição de formas de ler o mundo pelas crianças brasileiras, realizamos pesquisas sobre a leitura dos meios televisivos pelas crianças, que resultaram em vários artigos publicados em revistas e no livro Criança e televisão: leituras de imagens (PILLAR, 2001).

A fim de que nossas pesquisas regressassem às escolas subsidiando tanto a prática docente como a formação dos professores, o grupo criou com a Editora Mediação, a coleção Educação e Arte, onde foram publicadas algumas teses e dissertações. O primeiro número da coleção, lançado em 2002, foi Brincadeira e conhecimento, de Vera Bertoni dos Santos, que analisa o processo de criação teatral com as crianças de educação infantil. No ano seguinte, foram publicados os livros Imagens que falam ${ }^{4}$, de Maria Helena Rossi, que se centra na compreensão estética dos estudantes do ensino fundamental; $A$ formação do ator, de Mirna Spritzer, que abarca o processo de criação do aluno ator; e Filosofia da criação, de Marly Meira, que oferece uma reflexão sobre o significado do sensível em práticas estéticas contemporâneas. Em 2004, foi publicado o livro Criança e pintura, de Sandra Richter, um estudo sobre o processo de criação na linguagem da pintura com crianças de educação infantil.

\footnotetext{
${ }^{4}$ Este livro está na $5^{\mathrm{a}}$ edição e foi selecionado pelo Programa Nacional Biblioteca da Escola (PNBE, 2011), do Ministério da Educação, para fazer parte da biblioteca de mais de 41 mil escolas públicas brasileiras das redes federal, estadual e municipal.
} 
Outra forma de diálogo com pesquisadores e docentes para difundir nossos trabalhos foi através dos eventos. Foram realizados muitos eventos nesses 17 anos de GEARTE, dentre eles destacaremos, aqui, somente alguns. Em 2003, promovemos a I Jornada do GEARTE: Educação e Arte uma dança que se faz coletiva, com a participação de professores de artes de diversas cidades do estado do Rio Grande do Sul. Em julho de 2004, o Grupo organizou o curso Educação e os Muitos Sentidos do Sensível, como parte do XVIII Festival de Arte da cidade de Porto Alegre. Foram cinco oficinas, cada uma para um dos cinco sentidos, e conferências com a participação de João Francisco Duarte Jr., da Universidade de Campinas (UNICAMP); Malvina Dorneles, da UFRGS; João Jardim, diretor do filme Janela da Alma, e Neka Menna Barreto, chef.

Ainda no final de 1990, conhecemos os trabalhos de semiótica discursiva do Centro de Pesquisas Sociossemióticas (CPS) da Pontifícia Universidade Católica de São Paulo (PUC-SP), sob a direção de Ana Claudia de Oliveira (PUC-SP) e Eric Landowski, diretor do Centro de Pesquisa em Ciências Políticas de Paris (CNRS FNSP - CEVIPOF). Esses estudos permitiram um giro conceitual em nossas pesquisas sobre leitura de imagens. A semiótica discursiva desenvolvida por Greimas nos proporcionou bases teóricas e metodológicas para a análise em profundidade da produção de efeitos de sentido em nossas interações com as imagens da arte, dos meios de comunicação e da vida cotidiana. $O$ foco dos trabalhos se voltou para a análise do percurso gerativo, dos regimes de visibilidade, interação e sentido nos textos visuais, audiovisuais e sincréticos.

Para criar conexões com outros centros de pesquisa que estavam estudando a leitura de imagens da perspectiva da semiótica discursiva, promovemos e participamos de muitos eventos. Ana Claudia de Oliveira esteve conosco ministrando conferências, assessorando as pesquisas e participando como examinadora de dissertações e teses no grupo. Maria da Graça Krieger (UFRGS) fez a conferência Semiótica discursiva: fundamentos para a lexicografia e a terminologia. O grupo realizou o encontro vasas.cidades. Dos Alpes ao Ilha de Capri com Lucimar Frange, da Universidade Federal de Uberlândia (UFU), que apresentou seus estudos de pósdoutorado em semiótica e analisou trabalhos de mestrado e de doutorado. Sandra Ramalho e Oliveira, da Universidade do Estado de Santa Catarina (UDESC), fez a 
conferência Imagem também se lê e examinou teses. Moema Rebouças, da Universidade Federal do Espírito Santo (UFES), foi examinadora de trabalho de doutorado. Em 2010, o grupo promoveu a conferência Regimes de interação e sentido na educação com Eric Landowski e também uma reunião de assessoria às pesquisas. Lucia Teixeira, da Universidade Federal Fluminense (UFF), apresentou a conferência Autorretratos de Iberê Camargo e participou como examinadora de trabalhos de mestrado.

Nessa mesma época, o grupo se interessou pelos estudos de cultura visual realizados por Fernando Hernández, da Universidad de Barcelona (UB). Em 2003, em um encontro em Porto Alegre, apresentamos nossas pesquisas a Hernández e depois assinamos um acordo entre a UFRGS e a UB para intercâmbio e desenvolvimento de pesquisas, cursos e publicações. Através desse acordo, alguns participantes do GEARTE estudaram na Universidad de Barcelona e Fernando Hernández tem compartilhado a orientação de alunos em estágio de Doutorado Sanduíche, que trabalham na linha da cultura visual. Além disso, Hernández esteve em Porto Alegre, em diferentes momentos, realizando conferências, cursos e assessorando as pesquisas.

Em 2005, o grupo organizou um número especial sobre educação e arte para a Revista Educação \& Realidade ${ }^{5}$, em que procuramos mostrar a diversidade de teorias que subjazem nossas pesquisas e de que forma elas se articulam com estudos de pesquisadores nacionais e estrangeiros. Para divulgar os trabalhos realizados no GEARTE, também organizamos encontros nos quais os pesquisadores apresentam seus estudos. Promovemos uma série de palestras e conferências sobre educação e arte com a participação de professores de diversas universidades do país, entre os quais destacamos: Ana Mae Barbosa (USP/ Anhembi Morumbi), Sebastião Pedrosa (UFPE), Lucimar Frange (UFU), Fernando Azevedo (Departamento de Educação do Estado de Pernambuco), Mirian Celeste Martins (Universidade Mackenzie) e Marlene François (UNIJUI).

Em 2009, em parceria com a equipe do Santander Cultural de Porto Alegre, coordenado por Liliana Magalhães, organizamos o encontro Ensino da arte e

${ }^{5}$ A revista está no site (http://www.seer.ufrgs.br/index.php/educacaoerealidade/issue/view/921). 
Interterritorialidade com a participação de Ana Mae Barbosa (USP, AnhembiMorumbi); Ivone Richter (UFSM) e Lilian Amaral (UNESP), que reuniu mais de 300 pessoas. Em 2011, foi organizado o encontro Ensino da Arte, Abordagem Triangular e Culturas Visuais com Ana Mae Barbosa, Fernando Azevedo, Rosana Medeiros (Departamento de Educação da cidade de Canoas-RS); Maria Helena Rossi (UCS); Ruth Lerm e Donald Kerr Jr. (IFSul-Pelotas). Nesse mesmo ano, o grupo participou como um dos polos de transmissão simultânea do evento internacional Em nome das artes ou em nome dos públicos?, que ocorreu em Lisboa, Portugal, promovido pela Culturgest. Em 2012, no seminário 40 anos do PPGEDU6, o grupo apresentou um panorama das pesquisas em educação e artes visuais desenvolvidas no GEARTE.

De outubro de 2012 até março de 2013, com uma bolsa do governo brasileiro7, realizei um estágio de pós-doutorado na Faculdade de Belas Artes da Universidad Complutense de Madrid (UCM), sob supervisão de María Acaso e conheci o coletivo Pedagogias Invisíveis. Com grande interesse nos trabalhos de María Acaso e do coletivo Pedagogias Invisíveis, em 2013 o GEARTE organizou, em parceria com a Fundação Bienal do Mercosul, a vinda de María Acaso a Porto Alegre para uma conferência na Bienal, assessoria às pesquisas do GEARTE e realização do curso rEDUvolution: o Ensino da Arte como Processo de Criação Contemporânea, que congregou professores de diferentes áreas do conhecimento, redes e níveis de ensino, pesquisadores, artistas e mediadores.

O GEARTE é, então, um grupo interinstitucional que, em suas dissertações e teses, pesquisa as relações entre educação e arte, em diálogo com as áreas da semiótica discursiva, cultura visual, estética, história, teoria e crítica da arte. Está formado por professores e estudantes de pós-graduação da UFRGS, Universidade Pedagógica de Moçambique (UP), Instituto Federal de Educação, Ciência e Tecnologia Sul-Rio-Grandense, campus Pelotas (IFSul-Pelotas), Universidade Federal do Rio Grande do Norte (UFRN), Universidade de Caxias do Sul (UCS), Universidade de Joinville (UNIVILLE), Universidade Luterana do Brasil (ULBRA). O

\footnotetext{
${ }^{6}$ Programa de Pós-Graduação em Educação - UFRGS.

${ }^{7}$ Bolsa CAPES de Estágio Sênior Proc. BEX 5314/12-7.
} 
grupo está vinculado à linha de pesquisa Educação: Arte Linguagem Tecnologia do PPGEDU/UFRGS.

O grupo tem cinco linhas de atuação: pesquisa, docência, estudos específicos, assessoria e publicação. As pesquisas têm tematizado os vínculos entre educação e arte com o objetivo de contribuir para a expansão das perspectivas educativas da arte em diferentes contextos. Para promover nossas pesquisas, participamos em congressos nacionais e internacionais, publicamos artigos em revistas especializadas e organizamos livros. A Revista GEARTE surgiu de nosso interesse em reunir estudos e pesquisas realizados nessa área no país, em diálogo com trabalhos desenvolvidos em outros países.

As atividades de ensino e assessoria incluem seminários avançados na pósgraduação, cursos, palestras, encontros e conferências a cargo de especialistas do Brasil e de outros países. Ainda, em relação à docência, os participantes do GEARTE frequentemente colaboram com instituições diversas daquelas com as quais possuem vínculo permanente, gerando intercâmbio tanto com outras Universidades, quanto com diferentes instituições. Na Rede Gaúcha de Ensino Superior a Distância (REGESD) ${ }^{8}$ diversos participantes do grupo atuaram no curso de Graduação em Licenciatura em Artes Visuais como coordenadores, professores e tutores, viabilizando o oferecimento de um curso de graduação em licenciatura para professores atuantes na Educação Básica que abrangeu todo o estado, nessa modalidade. Tivemos, também, participantes que atuaram junto à Fundação Bienal de Artes Visuais do Mercosul $(F B A V M)^{9}$ na formação presencial e a distância de mediadores, bem como na coordenação pedagógica e supervisão destes profissionais durante diversas edições desta mostra.

Em nossas pesquisas, fizemos interlocuções com pesquisadores e teóricos de diversos países. Ana Mae Barbosa tem estado conosco em vários momentos, desde

\footnotetext{
${ }^{8}$ A REGESD foi uma Rede formada por 8 instituições de ensino que teve como objetivo principal promover, através da modalidade a distância, a formação superior de professores leigos da rede pública de ensino, que lecionavam disciplinas fora de sua área de formação.

${ }^{9}$ A FBAVM é uma entidade de direito privado, sem fins lucrativos, comprometida com a educação e o fomento à discussão sobre a Arte Contemporânea nos diferentes espaços e níveis de educação. Promove, desde 1997, uma exposição bianual voltada para a arte latino-americana que mobiliza grande parte do sistema artístico local.
} 
a criação do grupo, dando assessoria às pesquisas, conferências e participando como examinadora de dissertações e teses do grupo. Ana Claudia de Oliveira e Eric Landowski ministraram conferências e deram assessoria a nossas pesquisas. Fernando Hernández compartilhou a orientação de alunos de doutorado em instâncias de doutorado sanduíche. María Acaso esteve conosco em assessoria às pesquisas, curso e conferência. Realizamos, também, eventos com conferências de professores brasileiros e estrangeiros, lançamentos de livros, oficinas. Teóricos como Michael Parsons (Illinois University) e Jorge Larrosa (UB) participaram, de modo virtual ou presencial, de atividades junto ao grupo.

Durante esses 17 anos, muitas pessoas colaboraram com o grupo, pesquisadore ${ }^{10} \mathrm{e}$ estudantes. Nos primeiros anos do grupo, os professores e artistas que participaram do GEARTE eram de diversas áreas: artes visuais, teatro, música, psicologia e educação infantil. Alguns participantes mais tarde formaram seus próprios grupos de pesquisa em áreas específicas.

Com 21 pesquisadores brasileiros e estrangeiros de diversas instituições, o GEARTE tem procurado contribuir com seus trabalhos para a qualificação do ensino da arte no Brasil, tanto em espaços formais de educação como em espaços não formais. As conexões com outros pesquisadores, grupos de pesquisa nacionais e internacionais têm ampliado e aprofundado nossos estudos visando à construção de um lugar substancial para a arte na educação.

\section{Pedagogias Invisíveis e GEARTE: afinidades}

Para os dois coletivos, as pesquisas têm por foco qualificar o ensino da arte realizado em contextos educativos. $\mathrm{E}$, mais precisamente, a visualidade contemporânea tem instigado os pesquisadores dos dois grupos, seja por sua presença muito forte em nosso cotidiano, seja por suas complexas criações. Que visualidade é essa? Que textos a constituem? Que discursos atravessam essas

\footnotetext{
10 No PPGEDU muitos colegas foram parceiros em várias atividades. Gostaria de referir, em especial, os professores Dra. Esther Beyer, Dra. Regina Mutti, Dr. Fernando Becker, Dr. Nilton Fischer, Dr. Gabriel Junqueira, Dra. Margarete Axt, Dra. Malvina Dornelles, Dra. Rosa Fischer, Dra. Maria Stephanou, Dra. Luciana Loponte. Nas atividades conjuntas realizadas com o Instituto de Artes da UFRGS tivemos parceria das professoras Dra. Icléia Cattani e Dra. Mônica Zielinsky.
} 
produções? Como esses discursos se mostram? E qual o papel da educação, em geral, e do ensino da arte, em especial, na leitura dessa visualidade?

Assim, um dos enfoques das pesquisas realizadas em Pedagogias Invisíveis e no GEARTE têm sido a leitura das imagens que nos rodeiam e nos constituem, buscando conhecer os efeitos de sentido que produzem, desconsolidar o mundoimagem. Pretendemos que nossos trabalhos contribuam para a leitura de imagens, principalmente no ensino da arte, tanto na escola como em museus e em contextos comunitários. A consolidação de estudos sobre leitura de imagens no contexto atual, em que a informação visual é muito presente, pretende propiciar uma mudança no modo de interagirmos com as imagens, passando da contemplação à produção de efeitos de sentido acerca do que olhamos.

Em termos teóricos, ambos os coletivos têm fundamentado suas investigações na semiótica visual e na cultura visual, em diálogo com outras teorias, buscando que o processo de analisar a linguagem visual seja algo mais presente na educação. As pesquisas realizadas em Pedagogias Invisíveis fundamentam-se em Peirce, Eco e Jackson; enquanto no GEARTE, os referenciais têm sido Greimas, Landowski e os trabalhos do Centro de Pesquisas Sociossemióticas (PUC-SP). Além disso, os estudos da cultura visual têm perpassado nossas pesquisas subsidiando uma compreensão crítica das imagens e do papel das representações visuais.

Por fim, gostaríamos de dizer que nossa intenção é criar fluxos de pesquisas efervescentes entre Pedagogias Invisíveis e GEARTE para que se possa desenvolver trabalhos investigativos transdisciplinares e transoceânicos em conjunto, publicações, cursos e intercâmbio entre alunos e pesquisadores dos dois países. Nosso desejo, então, é o estabelecimento de uma rede internacional de pesquisa sobre leitura de imagens, com a participação de pesquisadores de diferentes universidades.

\section{Referências}

ACASO, Maria; ELLSWORTH, Elizabeth. El aprendizaje de lo inesperado. Madrid: Catarata, 2011. ACASO, Maria. Pedagogías invisibles: el espacio del aula como discurso. Madrid: Catarata, 2012. ACASO, Maria; NUERE, Silvia. El currículum oculto visual: aprender a obedecer a través de la imagen. Arte, Individuo y Sociedad, v. 17, p. 205-218, 2005. Disponível em: <http://revistas.ucm.es/index.php/ARIS/article/viewFile/ARIS0505110207A/5814>. Acesso em: fev.2014. 
ELLSWORTH, Elizabeth. Posiciones en la enseñanza: diferencia, pedagogía y el poder de la direccionalidad. Madrid: Akal, 2005.

PILLAR, Analice. Criança e televisão: leituras de imagens. Porto Alegre: Mediação, 2001.

PILLAR, Analice. (Org.). A educação do olhar no ensino das artes. 7.ed. Porto Alegre: Mediação, 2011.

PISCITELLI, Alejandro; ADAIME, Iván; BINDER, Inés. El proyecto Facebook y la Posuniversidad: sistemas operativos sociales y entornos abiertos de aprendizaje. Barcelona: Ariel, 2010. Disponível em: $<$ http://www.fundacion.telefonica.com/es/arte_cultura/ publicaciones/detalle/4>.Acesso em: fev.2014.

\section{María Acaso}

Professora Titular de Educação Artística na Faculdade de Belas Artes da Universidad Complutense de Madrid. Pesquisadora convidada nas Universidades de Stanford, Harvard, The School of the Arts Institute of Chicago, KHIB (Bergen National Academy of The Arts) e no Museu Getty. Implementou projetos antipedagógicos em La Casa Encendida, Fundação ICO, Fundação Telefônica. Tem diversos livros publicados. Fez programas de formação de educadores para Manifesta 8 e Fundação Telefônica.

E-mail - mariaacaso@gmail.com

Currículo - http://mariaacaso.blogspot.com.br/2011/04/cv.html

\section{Analice Dutra Pillar}

Professora Associada da Faculdade de Educação da Universidade Federal do Rio Grande do Sul, atuando na graduação e no PPGEDU. Doutora em Artes pela Universidade de São Paulo. Realizou estágio de pós-doutorado na Faculdade de Belas Artes da Universidad Complutense de Madrid. Pesquisadora do Conselho Nacional de Desenvolvimento Científico e Tecnológico (CNPq-Brasil). Publicou diversos artigos e livros. Participa do Conselho Editorial do International Journal of Education Through Art.

E-mail - analicedpillar@gmail.com

Currículo - http://lattes.cnpq.br/0033345213407184 